\title{
PERDAS DE SOLO E ÁGUA EM PLANTIO DE Acacia mangium WILD E SAVANA EM RORAIMA, NORTE DA AMAZÔNIA ${ }^{(1)}$
}

\author{
Luciana da Silva Barros ${ }^{(2)}$, José Frutuoso do Vale Jr. ${ }^{(3)}$, \\ Carlos Ernesto G.R. Schaefer ${ }^{(4)} \&$ Moisés Mourão Júnior ${ }^{(5)}$
}

\begin{abstract}
RESUMO
Plantios florestais de Acacia mangium constituem uma alternativa cada vez mais adotada em áreas de savanas do norte da Amazônia (Roraima) e podem causar alterações significativas de características do solo. Neste sentido, o objetivo deste estudo foi determinar perdas de solo e de água por erosão, que ocorrem em escoamento superficial (run off) em savana nativa e plantios de acácia na região Amazônica. Para isso, foram instaladas em duas fazendas, Santa Rita e Araçá, localizadas no município de Bonfim, na região da Serra da Lua, calhas coletoras de sedimentos, acopladas a caixas d'água, em Argissolo Vermelho-Amarelo. Foram determinadas a granulometria, a densidade aparente (Dap), a resistência à penetração (RP) e a velocidade de infiltração (VIB), bem como parâmetros físicos relacionados a perdas de solo. O delineamento experimental utilizado foi o de blocos ao acaso, com três tratamentos: cobertura natural de savana (SV), plantio de Acacia mangium com um ano de idade (P1) e plantio de Acacia mangium com quatro anos de idade ( $(\mathrm{P} 4)$, em três repetições. O experimento teve a duração de 12 meses (setembro de 2006 a agosto de 2007). Os resultados indicaram maiores perdas de solo e de água no plantio mais recente de acácia (P1), de savana nativa e do plantio com 4 anos (P4). Os resultados foram atribuídos à exposição do solo no período inicial de desenvolvimento da planta, ao selamento superficial e à coesão do solo. $O$ pico de perdas de solo ocorreu nos meses de abril a agosto, sendo o tipo de cobertura vegetal o fator determinante para redução das perdas de solo e de
\end{abstract}

\footnotetext{
(1) Parte da Dissertação de Mestrado do Primeiro Autor, apresentada a Pró-Reitoria de Pesquisa e Pós-Graduação do Programa de Pós-Graduação em Recursos Naturais da Universidade Federal de Roraima - UFRR.

${ }^{(2)}$ Pós-Graduanda do Curso de Recursos Naturais, Universidade Federal de Roraima - UFRR. BR 174, s/n, CEP $69304-000$ Boa Vista (RR). E-mail: lsbarros@hotmail.com

${ }^{(3)}$ Professor Associado II do Departamento de Solos e Engenharia Agrícola - UFRR. BR 174, s/n, CEP 69304-000 Boa Vista (RR). E-mail: vale.junior@click21.com.br

(4) Professor Associado II do Departamento de Solos - UFV, Av. PH Rolfs s/n, CEP 36570-000 Viçosa (MG). Bolsista CNPq. E-mail: Reyschaefer@yahoo.com.br

(5) Pesquisador da EMBRAPA AMAZÔNIA ORIENTAL - TV. Enéas Pinheiro s/n. Caixa postal 48, CEP 66095-100 Belém (PA). Email: mmourão@cpatu.embrapa.br
} 
água por erosão, sendo que as práticas de plantio no sentido do declive provavelmente agravaram as perdas de solo nos plantios de Acácia. Neste trabalho, a densidade do solo e o teor de matéria orgânica não representaram bons indicadores do tipo de manejo adotado na área.

Termos de indexação: Argissolo Vermelho-Amarelo, erosão hídrica, manejo florestal.

\author{
SUMMARY: SOIL AND WATER LOSSES IN ACACIA MANGIUM WILD \\ PLANTATIONS AND NATURAL SAVANNA IN RORAIMA, \\ NORTHERNAMAZON
}

\begin{abstract}
As an alternative land use of savanna areas in Roraima, commercial forest stands of Acacia mangium are being increasingly implemented. The purpose of this study was the in situ determination of soil and water losses in commercial stands of Acacia mangium and compare them with those under native savanna. The experiment was conducted on a RedYellow Argisol (Ultisol) in the region of Serra da Lua where Gerlach sediment and water collectors were installed. Soil density, texture, penetration resistance and infiltration rate were determined. All climate data were recorded by an automatic weather station placed within the experimental area. The experiment had a randomized block design with three treatments: oneyear-old Acacia stand (P1), four-year-old Acacia stand (P4); and native savanna (SV). All experimental data were collected within one year. Results indicated that greater soil and water losses occurred in younger Acacia plantations (P1), followed by savanna (SV) and four-yearold Acacia stands (P4). This was attributed to great soil exposure just after planting, when Acacia trees had not yet developed a good soil cover in these sealing-prone soils. The peak of soil and water loss occurred between April and August, and the practice of downslope planting aggravated soil erosion in Acacia stands. Soil bulk density or organic matter contents were not considered good management indicators for this area.
\end{abstract}

Index terms: Red Yellow Ultisols, soil erosion, forest management.

\section{INTRODUÇÃO}

As terras das savanas do estado de Roraima eram intensamente utilizadas na pecuária de corte extensiva, pequenas áreas com fruticultura e cultura de subsistência (Vale Júnior, 2000). Atualmente $57,3 \%$ de sua área é ocupada por terras indígenas, $35,2 \%$ por propriedades rurais e $4,4 \%$ por assentamentos de reforma agrária (Barbosa et al., 2007). Considerando as áreas ocupadas pelas propriedades rurais, $65 \%$ se concentram entre a capital Boa Vista e o município de Bonfim, com áreas que variam de 100 a 1.000 ha.

Esses solos têm sido aproveitados com culturas irrigadas, como arroz, soja, feijão, milho e hortaliças em geral, e para produção de madeira para exportação. A Acacia mangium Willd. Leguminosa arbórea (Mimosaceae) procedente da região Australásia (Marinho et al., 2004), que já ocupa mais de 25.000 ha nas savanas de Roraima, com tendência ao crescimento, tem sido plantada para esse fim.

Esses processos de ocupação e uso podem promover alterações na cobertura natural da região, provocando mudanças em características do solo, interferindo direta e indiretamente nas propriedades químicas, físicas e biológicas, alterando, assim, o equilíbrio dinâmico dos ecossistemas savânicos do norte da Amazônia (Vale Júnior, 2000).

A erosão, um dos processos resultantes destas alterações, é considerada por muitos autores (Cogo et al., 2004) como um dos maiores problemas ambientais, respondendo pelo declínio dos rendimentos das culturas, aumento dos custos de produção, e, por conseguinte, diminuindo a lucratividade das lavouras, além de provocar o assoreamento de rios, degradação da qualidade das águas, entre outros danos.

A erosão hídrica provocada pelo escoamento superficial (run off) carrega consigo sedimentos ricos em matéria orgânica e outras substâncias químicas, degradando os solos superficiais e vertentes. Vários fatores interferem na erosão, como as características das chuvas, a declividade do terreno e a capacidade e, ou, resistência do solo em absorver água, e a densidade da cobertura vegetal (Braun, 1961).

Os solos podem ser mais ou menos suscetíveis à erosão, dependendo de fatores intrínsecos e extrínsecos, que têm influência marcante sobre a erosão, destacando-se a pedoforma, textura, estrutura, taxa de infiltração de água no solo, presença de horizonte e, ou, camada coesa, teor de matéria orgânica, 
profundidade do solum e material de origem, classes de capacidade de uso do solo, técnicas de preparo e de cultivo (Alvarenga \& Souza, 1997; Souza, 1997, Cogo et al., 2003; Dechen, 2004).

A chuva é um dos elementos climáticos de maior importância na erosão do solo, visto que a erosão hídrica é a forma mais significante desse fenômeno no Brasil (Dechen et al., 2004).

Cogo et al. (2003), avaliando as perdas de solo e água por erosão hídrica, influenciada por diferentes métodos de preparo do solo, perceberam que as maiores perdas de solo ocorriam quando o período de maior erosividade das chuvas coincidia com a época de semeadura das culturas e o inicio de desenvolvimento das plantas, agravado pela utilização de técnicas de preparo que mobilizam muito o solo, como o preparo convencional, que expõe o solo à ação erosiva das chuvas.

Schaefer et al. (2002), analisando as perdas de solo, nutrientes, matéria orgânica e os efeitos microestruturais na formação do selamento de um Argissolo Vermelho-Amarelo sob chuva simulada, observaram o desenvolvimento de crostas ou selamento, que contribuíram para intensificar os efeitos da enxurrada, pois a destruição dos agregados do solo reduziu a taxa de infiltração.

A chuva tem seu trabalho acelerado quando aliada à topografia do terreno. Um exame mais atento da paisagem revela que a erosão tende a ser maior nos terrenos mais declivosos (Alvarenga \& Souza, 1997; Cogo et al., 2003). Souza et al. (2004), ao avaliar a variabilidade espacial de fatores de erosão em Latossolos sob diferentes formas de relevo, em áreas de cultivo de cana-de-açúcar, constataram que pequenas variações nas formas de relevo condicionam variabilidade diferenciada para os fatores de erosão do solo.

A cobertura vegetal, portanto, tem papel relevante por atenuar os impactos das gotas de chuva e diminuir a velocidade do escoamento superficial. Sua eficiência em reduzir as perdas de solo por erosão pode ser atribuída principalmente à proteção da superfície do solo proporcionada pelas plantas, impedindo o impacto direto das gotas de chuva sobre a superfície, diminuindo a desagregação do solo e resultando em baixa concentração de sedimentos do escoamento superficial (run off). Além disso, com a presença de plantas, grande quantidade de água é transpirada, reduzindo a umidade do solo, contribuindo para o aumento da taxa de infiltração e a redução do volume de escoamento superficial. Pode, ainda, haver aumento do teor de matéria orgânica (Dedececk et al., 1986; Segafredo et al., 1997; Leite et al., 2003), que, incorporada ao solo, melhora a drenagem (Lira, 1999), reduz a tendência ao encrostamento do solo, aumenta a rugosidade superficial, melhora a estrutura do solo e facilita a penetração das raízes dos vegetais (Braun, 1961; Bertoni \& Pestana, 1964; Foglino, 1965; Kiehl, 1985).
As variáveis físicas consideradas nos estudos de erodibilidade do solo, como profundidade, textura, permeabilidade e estrutura, vão determinar a tolerância à perda de solo das diversas classes de solo. Embora não seja conhecido um índice de erodibilidade universalmente aceito para todas as classes de solo, Araújo et al. (2005) e Alvarenga \& Souza (1997) acreditam que, por meio do conhecimento das características que influenciam a suscetibilidade do solo à erosão e da ocorrência de solos mais erodíveis em determinada região, é possível a tentativa de prever e avaliar os impactos ambientais, bem como indicar medidas que visem aumentar a resistência do solo ou diminuir as forças do processo erosivo.

Considerando o limitado conhecimento sobre perdas de solo em sistemas silviculturais no norte da Amazônia, o objetivo deste estudo foi determinar as perdas de solo e água em plantios de Acacia mangium, com diferentes idades (1 e 4 anos), comparadas à savana natural na região norte da Amazônia brasileira.

\section{MATERIAL E MÉTODOS}

O estudo foi conduzido nas Fazendas Araçá e Santa Rita, pertencentes ao Empreendimento Ouro Verde Agrossilvopastoril Ltda., na região da Serra da Lua, município de Bonfim, localizadas a $44 \mathrm{~km}$ da capital Boa Vista, como parte da microbacia do Rio Quitauau, tributário da margem esquerda do Rio Branco. O experimento localiza-se no quadrante das coordenadas geográficas $2^{\circ} 33^{\prime} 36$ " e $2^{\circ} 43$ ' 12 " N / 6019 ' 12 " e $60^{\circ} 24$ ' $00^{\prime}$ "W. De acordo com a classificação de Köppen, o clima da região é do tipo Awi. O solo da área experimental é Argissolo Vermelho-Amarelo distrófico, textura média, com relevo suave ondulado e declividade média de $8 \%$. Os solos são de baixa fertilidade natural e $\mathrm{pH}$ ácido. A cobertura vegetal original é de cerrado strictu sensu (savana) de Roraima.

O experimento foi realizado em plantio de Acácia de 2003, na Fazenda Araçá, plantios de 2005 na Fazenda Santa Rita, e em vegetação natural de savana, por um período de 12 meses em 2006.

Os tratamentos foram: (a) plantio jovem (P1) plantas com 1 ano de idade, manejo convencional (1 subsolagem a $60 \mathrm{~cm}$ e 2 gradagens) e linhas de plantas no sentido do declive; (b) plantio estabelecido (P4) plantas com 4 anos de idade e linhas no sentido do declive; e (c) savana natural (SV) - cobertura natural sem antropização.

Três quadras coletoras de erosão (dimensão de $1 \mathrm{x} 10 \mathrm{~m}$ ou $10 \mathrm{~m}^{2}$ ) foram instaladas em cada tratamento, posicionadas sempre no sentido da declividade, e espaçadas $3 \mathrm{~m}$ entre si. As quadras foram protegidas com tábuas de $20 \mathrm{~cm}$ de largura nas laterais, isolando-as dos demais talhões, e servindo também como proteção para evitar a entrada ou saída 
de sedimentos. No final de cada quadra, foi acoplada uma calha coletora, totalizando nove quadras do tipo Gerlach (1967) (Figura 1). As calhas serviram como receptoras de sedimentos e água do escoamento superficial.

Cada calha foi conectada a uma caixa d'água de $500 \mathrm{~L}$ por um cano de PVC (50 mm), sendo enterrada no solo e fixada com pinos sobre uma base de concreto para evitar seu deslocamento.

Também foram acoplados canos de PVC de $50 \mathrm{~mm}$ de diâmetro na borda superior das caixas para servir como "ladrão".

Na saída dos canos provenientes das calhas que desembocavam dentro das caixas d'água, sacos de malha PV de $30 \times 40 \mathrm{~cm}$ foram colocados com o objetivo de acumular e reter os sedimentos mais grosseiros (areia) e deixar passar água e sedimentos mais finos (silte e argila) para caixa d'água. Em cada ponto de conexão dos canos da caixa d'água, vedou-se a conexão com massa de modelar para impedir a entrada de sedimentos e água fora das quadras.

Com a ajuda de uma régua graduada de $1,50 \mathrm{~m}$ de altura, antes de cada coleta, media-se a altura da lâmina d'água acumulada nas caixas a cada chuva.

A coleta de sedimentos consistiu em retirar das calhas e dos sacos de malha PV, o material acumulado (areia, silte e argila) proveniente do escoamento superficial. O material coletado foi homogeneizado e acondicionado em frascos de vidro de $1 \mathrm{~L}$, devidamente etiquetados e identificados com o nome da unidade experimental e com respectivo número de repetição (P11, P12, P13; P41, P42, P43 e SV1, SV2, SV3) datados (dia/mês/ano). Posteriormente foram levados ao Laboratório do Núcleo de Recursos Naturais NUREN, da Universidade Federal de Roraima no Campus Cauamé, para a realização das análises.

Os dados coletados foram submetidos à Análise de Variância (ANOVA) segundo o delineamento experimental de blocos ao acaso, com três tratamentos e três repetições. Quando constatada a significância

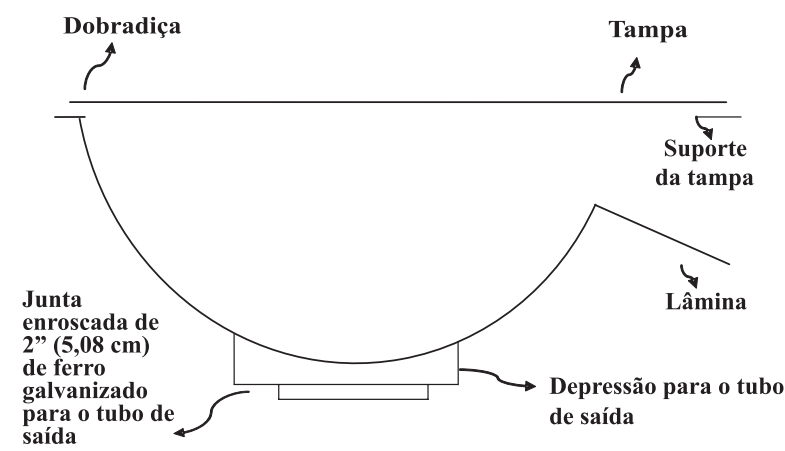

Figura 1. Dimensões da calha coletora de sedimentos utilizada nos tratamentos SV, P1 e P4 na região da Serra da Lua, Bonfim, norte do Estado de Roraima (Gerlach, 1967). pelo teste $\mathrm{F}$, as médias foram comparadas pelo teste de Tukey a $5 \%$.

\section{RESULTADOS E DISCUSSÃO}

\section{Perdas de Solo e Água por Escoamento Superficial - run off}

As maiores perdas de solo foram registradas para o tratamento $\mathrm{P} 1$, com média de $1,16 \mathrm{t} \mathrm{ha}^{-1}$, o qual foi seguido do tratamento SV com $0,33 \mathrm{t} \mathrm{ha}^{-1}$ e P4 com $0,11 \mathrm{t} \mathrm{ha}^{-1}$ no ano (Quadro 1).

Houve diferença significativa $(p<0,05)$ nos valores médios da perda de solo no mês de abril, nas três unidades experimentais. Nos meses seguintes, a unidade P1 apresentou diferença significativa em relação à unidade $\mathrm{P} 4 \mathrm{e} \mathrm{SV}$. Contudo $\mathrm{P} 4 \mathrm{e} \mathrm{SV}$ não se diferiram significativamente, demonstrando um comportamento semelhante entre si quanto às perdas de solo nos meses de maio a agosto. Quanto aos valores acumulados, verificou-se que todos os tratamentos diferiram significativamente.

As médias de perdas de água dos tratamentos nos meses de abril, maio e agosto apresentaram diferenças significativas, e nos meses de junho e julho não houve diferenças significativas (Quadro 1).

Considerando os principais fatores que influenciam a erosão descrita por diversos autores (Bertoni, 1959; Mota, 1981; Derpsch et al., 1991; Alvarenga \& Souza, 1997; Bertoni \& Lombardi Neto, 1999; Lira, 1999; Dechen et al., 2004), esperar-se-ia que o tratamento $\mathrm{P} 1$, cuja área foi convertida de savana para plantios de acácia, revelasse maior escoamento superficial e perdas de solo. Isso decorreria do fato de que, após a etapa de preparação do solo para plantio, com a remoção da cobertura natural, revolvimento e destruição dos agregados do solo, no manejo convencional, as partículas do solo tornar-se-iam mais vulneráveis ao splash das gotas de chuva e, consequentemente, ao escoamento superficial (run off).

A ausência de proteção do solo devido à remoção da cobertura vegetal para o plantio em P1, combinada aos períodos de maior precipitação, que foram os de maior erosividade, de abril a agosto, tornou o horizonte A mais suscetível à enxurrada, o que está em acordo com Dedececk et al. (1986), Seganfredo et al. (1997), Leite et al. (2003) e Cogo et al. (2003), que afirmam que a cobertura vegetal oferece a proteção necessária ao solo durante chuvas altamente erosivas.

$\mathrm{Na}$ área de savana natural (SV), a enxurrada foi atenuada pela cobertura vegetal presente, embora não tão densa e protegida quanto na unidade P4. A presença de gramíneas contribuiu para maior proteção contra os impactos das gotas de chuva, bem como a melhoria da capacidade de infiltração do solo, comprovada pelas análises (Quadro 2), reduzindo suas taxas de perdas de água por escoamento superficial e 
de solo a 6,25 x $10^{5} \mathrm{~mm} \mathrm{ha}^{-1} \mathrm{ano}^{-1}$ e $0,33 \mathrm{t} \mathrm{ha}^{-1} \mathrm{ano}^{-1}$, respectivamente.

Na unidade $\mathrm{P} 1$, por ser de textura areia franca no horizonte $\mathrm{A}$ (11,14 \% de argila) (Quadro 2), com maior macroporosidade, poder-se-iam esperar maiores taxas de infiltração (Bertoni \& Lombardi Neto, 1999). Apesar disso, foi evidenciada nesta unidade a menor taxa de infiltração dentre todas $\left(2,17 \mathrm{~cm} \mathrm{~h}^{-1}\right)$ promovendo, por conseguinte, maior volume de enxurrada, evidenciado pelo volume total de água, 1.01 x $10^{6} \mathrm{~mm} \mathrm{ha}^{-1} \mathrm{ano}^{-1}$, consequentemente, maior taxa de perdas de solo. Essa perda de água, além das consequências esperadas com relação à erosão, reduz a disponibilidade deste recurso à planta e aumenta o déficit hídrico na época da estiagem.

Embora tenha sido verificado um aumento do teor de matéria orgânica no horizonte superficial nos plantios de acácia (P1 e P4), o que poderia contribuir para melhoria na estruturação do solo decorrente da incorporação dos restos da vegetação original, foi observada uma destruição dos agregados do solo no manejo convencional (preparo do solo para o plantio), causando a pulverização superficial. Assim, como as partículas mais finas e dispersas tendem a preencher os poros após as chuvas, o impacto das gotas de chuva promoveu o selamento superficial observado em campo (Bertoni \& Pestana, 1964; Foglino, 1965; Kiehl, 1985; Lira, 1999, Schaefer et al., 2002).

Apesar de o preparo do solo convencional visar diminuir a compactação e facilitar o enraizamento das plantas, este acabou contribuindo para vulnerabilidade do solo à erosão nas condições do plantio de acácia, já que no início do desenvolvimento das plantas, o solo se mostrou muito exposto.

Quadro 1. Valores médios de perda de solo e água no período de janeiro a agosto de 2007

\begin{tabular}{|c|c|c|c|c|c|c|}
\hline \multirow{2}{*}{ Unidade } & \multicolumn{6}{|c|}{ Mês } \\
\hline & Abril & Maio & Junho & Julho & Agosto & Total \\
\hline & \multicolumn{6}{|c|}{ Perdas de solo } \\
\hline $\mathrm{P} 4$ & $0,00 \mathrm{c}$ & $0,02 \mathrm{~b}$ & $0,03 \mathrm{~b}$ & $0,04 \mathrm{~b}$ & $0,03 \mathrm{~b}$ & $0,11 \mathrm{c}$ \\
\hline $\mathrm{P} 1$ & 0,38 a & 0,19 a & $0,13 \mathrm{a}$ & 0,13 a & $0,34 \mathrm{a}$ & 1,16 a \\
\hline SV & $0,11 \mathrm{~b}$ & $0,02 \mathrm{~b}$ & $0,03 \mathrm{~b}$ & $0,01 \mathrm{~b}$ & $0,17 \mathrm{ab}$ & $0,33 \mathrm{~b}$ \\
\hline \multirow[t]{2}{*}{ Média } & 0,16 & 0,08 & 0,06 & 0,06 & 0,18 & \\
\hline & \multicolumn{6}{|c|}{$\begin{array}{r}\text { Perdas de água } \\
\mathrm{mm} \mathrm{ha}^{-1} \text { ano }^{-1}\end{array}$} \\
\hline $\mathrm{P} 4$ & $0,00 \mathrm{~b}$ & $6,67 \times 10^{3} \mathrm{~b}$ & $7,90 \times 10^{4} \mathrm{a}$ & $1,43 \times 10^{5} \mathrm{a}$ & $4,91 \times 10^{4} \mathrm{~b}$ & $2,76 \times 10^{5} \mathrm{c}$ \\
\hline $\mathrm{P} 1$ & $2,30 \times 10^{5} \mathrm{a}$ & $1,59 \times 10^{5} \mathrm{a}$ & $1,75 \times 10^{5} \mathrm{a}$ & $1,79 \times 10^{5} \mathrm{a}$ & $2,71 \times 10^{5} \mathrm{a}$ & $1,01 \times 10^{6} \mathrm{a}$ \\
\hline $\mathrm{SV}$ & $2,75 \times 10^{4} \mathrm{~b}$ & $2,52 \times 10^{4} \mathrm{~b}$ & $2,01 \times 10^{5} \mathrm{a}$ & $1,36 \times 10^{5} \mathrm{a}$ & $2,35 \times 10^{5} \mathrm{a}$ & $6,25 \times 10^{5} \quad b$ \\
\hline Média & $8,59 \times 10^{4}$ & $6,39 \times 10^{4}$ & $1,52 \times 10^{5}$ & $1,53 \times 10^{5}$ & $1,85 \times 10^{5}$ & \\
\hline
\end{tabular}

${ }^{(1)}$ Médias seguidas da mesma letra não diferem entre si pelo teste de Tukey a $5 \%$.

Quadro 2. Composição granulométrica, velocidade de infiltração de água, densidade e resistência à penetração nas unidades experimentais $\mathrm{SV}, \mathrm{P} 1, \mathrm{P} 4$

\begin{tabular}{|c|c|c|c|c|c|c|c|c|}
\hline \multirow{2}{*}{ UE } & \multicolumn{2}{|c|}{ Horizonte } & \multicolumn{3}{|c|}{$\begin{array}{c}\text { Composição } \\
\text { granulométrica }\end{array}$} & \multirow{2}{*}{ Densidade } & \multirow{2}{*}{$\begin{array}{l}\text { Velocidade de } \\
\text { infiltração }\end{array}$} & \multirow{2}{*}{$\begin{array}{c}\text { Resistência à } \\
\text { penetração }\end{array}$} \\
\hline & Símbolo & Prof undidade & Areia & Silte & Argila & & & \\
\hline \multirow{4}{*}{ SV } & & $\mathrm{cm}$ & \multicolumn{3}{|c|}{$-\mathrm{g} \mathrm{kg}^{-1}$} & $\mathrm{~g} \mathrm{~cm}^{-3}$ & $\mathrm{~cm} \mathrm{~h}^{-1}$ & $\mathrm{kgf} \mathrm{cm}^{-3}$ \\
\hline & $\mathrm{A}$ & $\begin{array}{r}0-10 \\
10-20\end{array}$ & 796 & 97 & 107 & $\begin{array}{l}1,49 \\
1,49\end{array}$ & 15,63 & 15,2 \\
\hline & $\mathrm{Bt}$ & $\begin{array}{l}10-20 \\
20-30\end{array}$ & 764 & 14 & 222 & 1,58 & & $\begin{array}{l}10,5 \\
19,5\end{array}$ \\
\hline & & $30-40$ & & & & 1,63 & & 29,3 \\
\hline \multirow[t]{4}{*}{$\mathrm{P} 1$} & $\mathrm{~A}$ & $0-10$ & 802 & 84 & 114 & 1,34 & 2,17 & 12,3 \\
\hline & & $10-20$ & & & & 1,57 & & 17,7 \\
\hline & $\mathrm{Bt}$ & $20-30$ & 692 & 63 & 245 & 1,67 & & 29,1 \\
\hline & & $30-40$ & & & & 1,70 & & 32,0 \\
\hline \multirow[t]{4}{*}{$\mathrm{P} 4$} & $\mathrm{~A}$ & $0-10$ & 711 & 116 & 173 & 1,28 & 16,63 & 13,0 \\
\hline & & $10-20$ & & & & 1,49 & & 6,9 \\
\hline & $\mathrm{Bt}$ & $20-30$ & 563 & 143 & 294 & 1,65 & & 20,8 \\
\hline & & $30-40$ & & & & 1,68 & & 29,3 \\
\hline
\end{tabular}


Outro fator que contribuiu para as perdas de solo e água no sistema de plantio de acácia foi a disposição a favor do declive (morro abaixo), promovendo um aumento da energia cinética do escoamento superficial, permitindo remover uma quantidade muito maior de solo (Alvarenga \& Souza, 1997; Cogo et al., 2003). Tal prática é comum em muitos plantios da região.

O gradiente textural dos Argissolos, associado à declividade da área também corrobora os dados apresentados, e está consistente com diversos autores (Ramalho Filho \& Beek, 1995; Bertoni \& Lombardi Neto, 1999; Dechen et al., 2004) que consideram estes fatores preponderantes para as perdas de solo arável.

É possível que a densidade aparente (Dap) tenha influência nas perdas de solo por erosão. Os resultados mostraram valores absolutos relativamente elevados, especialmente em profundidade, indicando processo de coesão natural, típica dos solos sob savana em Roraima (Schaefer, 1997). Embora não tenha sido verificada diferença significante entre as médias das unidades experimentais (Quadro 3), o aumento da densidade aparente e da coesão em profundidade nos solos de savana compromete a permeabilidade, favorecendo também as perdas de solo, como destacam Alvarenga \& Souza (1997) e Beutler et al. (2003) em outras regiões.

Os dados obtidos na unidade P1 apenas representam o período inicial da cultura, quando as condições são muito favoráveis à erosão, que tende à redução com o desenvolvimento das árvores e, consequentemente, com o aumento da cobertura vegetal e com a formação da liteira, que deverá servir de proteção às enxurradas e melhoria das condições físicas e químicas do solo (Cardoso et al., 2004). Situação semelhante foi apresentada por Pires \& Silva (2005) que também observaram a redução de erosão nos plantios de eucalipto da região centro-leste de Minas, com o desenvolvimento da cultura, reduzindo as perdas a valores bem inferiores aos da tolerância para os solos daquela região.

Quadro 3. Valores médios de densidade aparente, ordenados segundo o teste de Tukey e Análise de Variância

\begin{tabular}{|c|c|c|c|c|}
\hline \multirow{2}{*}{ Unidade } & \multicolumn{4}{|c|}{ Profundidade (cm) } \\
\hline & {$[00-10]$} & {$[10-20]$} & {$[20-30]$} & [30 - 40] \\
\hline & \multicolumn{4}{|c|}{$-\mathrm{g} \mathrm{cm}^{-3}$} \\
\hline $\mathrm{P} 1$ & $1,34 \mathrm{~b}$ & $1,57 \mathrm{a}$ & $1,67 \mathrm{a}$ & $1,70 \mathrm{a}$ \\
\hline $\mathrm{P} 4$ & $1,28 \mathrm{~b}$ & $1,49 \mathrm{a}$ & $1,65 \mathrm{a}$ & $1,68 \mathrm{a}$ \\
\hline SV & $1,49 \mathrm{a}$ & $1,49 \mathrm{a}$ & $1,58 \mathrm{a}$ & $1,63 \mathrm{a}$ \\
\hline
\end{tabular}

Valores precedidos de mesma letra não diferem significativamente, segundo o teste de Tukey a $0,5 \%$.
Outro aspecto a considerar é que a unidade SV não sofreu o impacto do revolvimento apresentado na unidade $\mathrm{P} 1$, o que provavelmente manteve o equilíbrio natural da agregação do solo, evidenciado pelas análises físicas, que demonstraram uma boa taxa de infiltração $\left(15,63 \mathrm{~cm} \mathrm{~h}^{-1}\right)$, bem superior a $\mathrm{P} 1$, e a manutenção dos agregados do solo, apesar de maior densidade aparente nos primeiros $10 \mathrm{~cm}\left(1,49 \mathrm{~g} \mathrm{~cm}^{-3}\right)$, e maior resistência à penetração $\left(15,2 \mathrm{kgf} \mathrm{cm}^{-2}\right)$. Esses resultados estão associados a pouca proteção ao solo oferecida pela savana natural em Roraima, onde há uma vegetação graminosa rala e esparsa, permitindo incidência direta das gotas das chuvas e radiação solar sobre a superfície do solo, os quais promovem ciclos alternados de umedecimento e secagem, consequentemente tornando o solo mais compactado nos primeiros centímetros. Além de os solos de savana serem muito expostos e naturalmente degradados (Schaefer, 1997), o potencial erosivo das chuvas muito concentradas na região é elevado, com grande energia cinética.

A unidade $\mathrm{P} 4$ apresentou-se bem mais protegida que as demais unidades, o que gerou, por conseguinte, as menores perdas de água por escoamento superficial e perdas de solo por erosão, registrando-se a média de perda de água e solo de $2,76 \times 10^{5} \mathrm{~mm} \mathrm{ha}^{-1} \mathrm{ano}^{-1} \mathrm{e}$ $0,11 \mathrm{t} \mathrm{ha}^{-1} \mathrm{ano}^{-1}$, respectivamente.

O controle da erosão se deu devido aos efeitos da redução no impacto da precipitação no solo, consequência da interceptação das gotas de chuva pelas copas das árvores, acúmulo de folhas na camada superficial do solo, maior teor de matéria orgânica, que condiciona melhor agregação ao solo, estrutura e permeabilidade e, consequentemente, o aumento da infiltração da água, com a maior taxa, $16,63 \mathrm{~cm} \mathrm{~h}^{-1}$ (Quadro 3). Resultados semelhantes foram encontrados por Martins et al. (2003) nos sistemas florestais da região de Aracruz no Espírito Santo, que registraram perdas que variavam de 0,21 a $3,20 \mathrm{Mg} \mathrm{ha}^{-1}$ ano $^{-1}$, também em um Argissolo Amarelo, atribuindo os resultados à proteção que a cultura oferecia ao solo e ao manejo conservacionista utilizado, concorrendo, portanto, para redução do escoamento superficial da água e menores perdas de solo.

Com relação ao manejo utilizado, Leite et al. (2003) observaram que as práticas de cultivo mínimo reduziram em $70 \%$ as perdas de solo comparado ao sistema convencional e morro abaixo, visto terem reduzido a velocidade, a tensão, o cisalhamento do escoamento superficial, concluindo-se, portanto, que as perdas solo e água nos plantios de acácia poderiam também ser reduzidas com a utilização de práticas simples de manejo, como plantio em nível.

Na comparação das perdas médias de solo das três unidades experimentais, nota-se que as perdas de solo na unidade $\mathrm{P} 1$ são aproximadamente 3,5 vezes maiores que as perdas de solo SV e aproximadamente 10,5 vezes maiores que as da unidade P4. Estudos de perdas de solo na região do Apiaú, no estado de Roraima, 
apresentados por Barbosa \& Fearnside (2000), comparando uma pastagem e floresta primária, indicam que a perda de solo da pastagem com Brachiaria humidicola é sete vezes maior que na floresta primária. Embora a magnitude entre as perdas seja diferente da observada neste estudo, confirma-se a importância da cobertura vegetal para a proteção contra erosão.

A análise estatística revelou diferenças significativas quanto à resistência à penetração $(\mathrm{RP})$ nos primeiros $20 \mathrm{~cm}$ do solo entre as unidades (Quadro 4), observando-se o aumento da RP em profundidade, que provavelmente está associado ao processo de coesão natural presente nas savanas (Schaefer, 1997; Vale Júnior., 2000), que certamente contribui para o nível de compactação encontrado, independentemente do sistema (P1, P4 ou SV) (Vale Júnior, 2000, 2005, 2007).

As perdas de solo registradas neste experimento, no período considerado foram muito aquém dos limites da tolerância, proposto por Bertoni \& Lombardi Neto (1999), para a classe de solo dos Argissolos, que vai de 9,6 a $15 \mathrm{t} \mathrm{ha}^{-1} \mathrm{ano}^{-1}$, coincidindo com o encontrado por diversos autores (Beutler et al., 2003; Martins et al., 2003; Brito et al., 2004).

Quadro 4. Valores médios de resistência à penetração, ordenados segundo o teste de Tukey e análise de variância

\begin{tabular}{lccccc}
\hline \multirow{5}{*}{ Unidade } & \multicolumn{5}{c}{ Profundidade } \\
\cline { 2 - 5 } & {$[\mathbf{0 0 - 1 0 ]}$} & {$[\mathbf{1 0}-\mathbf{2 0}]$} & {$[\mathbf{2 0 - 3 0 ]}$} & {$[\mathbf{3 0}-\mathbf{4 0}]$} \\
\cline { 2 - 5 } & \multicolumn{5}{c}{ kgf cm ${ }^{2}$} \\
P1 & $12,3 \mathrm{~b}$ & $17,7 \mathrm{a}$ & $29,1 \mathrm{a}$ & $32,0 \mathrm{a}$ \\
P4 & $13,0 \mathrm{ab}$ & $16,9 \mathrm{ab}$ & $20,8 \mathrm{~b}$ & $29,3 \mathrm{~b}$ \\
SV & $15,2 \mathrm{a}$ & $15,5 \mathrm{~b}$ & $19,5 \mathrm{~b}$ & 29,3 & $\mathrm{~b}$ \\
Total & 13,5 & 16,7 & 23,1 & 30,2 \\
\hline
\end{tabular}

Médias seguidas da mesma letra não diferem entre si pelo teste de Tukey a $5 \%$.

\section{CONCLUSÕES}

1. As maiores perdas de solo e água foram observadas na fase de estabelecimento da cultura da acácia, antes do fechamento das copas, sendo concentradas em abril e agosto, meses mais chuvosos na região de savanas de Roraima. Com quatro anos de estabelecimento da cultura, houve notável redução das perdas de solo e água, inferior até na savana natural.

2. No período avaliado, que pode ser considerado relativamente curto, a densidade do solo ou os teores de matéria orgânica em superfície não foram bons indicadores de manejo e não indicaram degradação, já que os solos sob savana em Roraima são, em geral, naturalmente compactados, e modificações mensuráveis devem levar tempo maior para ocorrer.
3. A cobertura vegetal mais densa dos plantios de acácia foi o fator que mais contribuiu para redução das perdas de solo por erosão; o plantio de acácia a favor do declive, comum na região, contribui para o aumento da enxurrada em curto prazo, favorecendo com isso as perdas de solo por erosão.

\section{AGRADECIMENTOS}

À Pró-Reitoria de Pesquisa e Pós Graduação, responsável pelo Programa de Pós-Graduação em Recursos Naturais da Universidade Federal de Roraima, e aos Empreendimentos Ouro Verde Agrossilvopastoril Ltda.

\section{LITERATURA CITADA}

ALVARENGA, M.I.N. \& SOUZA, J.A. Atributos do solo e impacto ambiental. 2.ed. Lavras, UFLA/FAEPE, 1997. 205p.

ARAÚJO. G.H.S.; ALMEIDA, J.R. \& GUERRA, A.J.T. Gestão ambiental de áreas degradadas. Rio de Janeiro, Bertrand Brasil, 2005. 320p.

BARBOSA, R.I. \& FEARNSIDE, P.M. Erosão do solo na Amazônia: Estudo de caso na região do Apiaú, Roraima, Brasil. Acta Amaz., 30:601-613, 2000.

BARBOSA, R.I.; CAMPOS, C.; PINTO, F. \& FEARNSIDE, P.M The "lavrado of Roraima biodiversity and conservation of Brasil's Amazônia Savannas. Functional Ecossistems and Communities. Global Science Books. 1: 29-41. 2007. Disponivel em: < http://philip.inpa.gov.br/publ_livres/ Preprints / $2007 /$ B i o diversity \% 20 i n \% 20Lavrado\%20of\%20Roraima-5a.pdf $>$ acesso em: 09/10/ 2007.

BERTONI, R. \& PESTANA, F.I. Relação chuva/perdas por erosão em diferentes tipos de solos. Bragantia, 23:3-11, 1964.

BERTONI, J. O espaçamento de terraços em culturas anuais, determinado em função das perdas por erosão. Bragantia, 18:113-140, 1959.

BERTONI, J. \& LOMBARDI NETO, F. Conservação do solo. 4.ed. São Paulo, Ícone, 1999. 355p.

BEUTLER, J.F.; BERTOL, I.; VEIGA, IM. \& WILDNER, L.P. Perdas de solo e água num Latossolos Vermelho aluminoférrico submetido a diferentes sistemas de preparo e cultivo sob chuva natural. R. Bras. Ci. Solo, 27:509-517, 2003 .

BRITO, L.F.; PIRES, L.S.; SILVA, M.L.N.; CURI, N.; LEITE, F.P. \& OLIVEIRA, F.P. Erosão hídrica de um Latossolos vermelho distrófico típico em areas de pós-plantio de eucalipto na região de Guanhães - Minas Gerais: In: REUNIÃO BRASILEIRA DE MANEJO E CONSERVAÇÃO DE SOLO E ÁGUA: Manejo integrado a ciência do solo na produção de alimentos, 15., Santa Maria, 2004. Anais. Santa Maria, Universidade Federal de Santa Maria, 2004. p.1-25. 
BRAUN, W.A. Contribuição ao estudo da erosão no Brasil e seu controle. R. Bras. Geografia, 4:591-642, 1961.

CARDOSO, D. P. \& SILVA, M. L. N. \& CURI, N. \& SÁFADI, T. \& FONSECA, S. \& FERREIRA M. M. \& MARTINS, S. G. \& MARQUES, J.J.G.S.M. Erosão hídrica avaliada pela alteração na superfície do solo em sistemas florestais. Sci. For., 66:25-37, 2004.

COGO. N.P.; DENARDIN, J.E.; BERTOL, I. \& KOCHHANN, R.A. Retomada, redefinição e intensidade da pesquisa em erosão do solo no Brasil. In: REUNIÃO BRASILEIRA DE MANEJO E CONSERVAÇÃO DO SOLO E DA ÁGUA, MANEJO INTEGRADO A CIÊNCIA DO SOLO NA PRODUÇÃO DE ALIMENTOS, 15., Santa Maria, 2004. Anais. Santa Maria, Universidade Federal de Santa Maria, 2004. p.1-26.

COGO, N.P.; LEVIEN, R. \& SCHWARZ, R.A. Perdas de solo e água por erosão hídrica influenciadas por métodos de preparo, classes de declive e níveis de fertilidade do solo. R. Bras. Ci. Solo, 27:743-753, 2003.

DEDECEK, R.A.; RESK, D.V.S. \& FREITAS, J.E. Perdas de solo, água e de nutriente por erosão em Latossolo Vermelho -Escuro dos Cerrados em diferentes cultivos sob chuva natural. R. Bras. Ci. Solo, 10:256-272, 1986.

DECHEN, S.C.F.; DE MARIA, I.C.; CASTRO, O.M. \& VIEIRA, S.R. Manejo de solos tropicais no Brasil. In: REUNIÃO BRASILEIRA DE MANEJO E CONSERVAĈ̃O DO SOLO E DA ÁGUA, MANEJO INTEGRADO A CIÊNCIA DO SOLO NA PRODUÇÃO DE ALIMENTOS, 15., Santa Maria, 2004. Anais. Santa Maria, Universidade Federal de Santa Maria, 2004. p.1-25.

DERPSCH, R.; ROTH, C.H.; SIDIRAS, N. \& KOPE, U. Controle de erosão no Paraná: Sistemas de cobertura do solo, plantio direto e preparo conservacionistas do solo. Eschborn, IAPAR/GTZ, 1991. 272 p.

GERLACH, T. Hillslope troughs for measuring sediment movement. Rev. Géomorph. Dynam., 7:173, 1967.

FOGLINO, E. La lotta antierosiva en Ecuador. R. Agropec. Subtropical Tropical, 59:10-12,1965.

KIEHL, E.J. Fertilizantes orgânicos. Piracicaba, Ceres, 1985. $492 p$.

LEITE, M.H.S.; AMORIM, A. \& COUTO, R. Avaliação das perdas de solo sob diferentes condições de manejo do solo. In: REUNIÃO BRASILEIRA DE MANEJO E CONSERVAÇ̃̃O DO SOLO E DA ÁGUA, Novos desafios do carbono no manejo conservacionista. 16., Aracajú, 2006. Anais. Aracajú, 2006. p.1-4.

LIRA, A.C.S. Comparação entre povoamento de eucalipto sob diferentes práticas de manejo e vegetação natural de cerradão, através da respiração, infiltração de água da mesofauna do solo. Piracicaba, Escola Superior de Agricultura Luiz de Queiroz, 1999.70p.(Tese de Mestrado)
MARINHO, N.F.; CAPRONI, A.L.; FRANCO, A.A. \& BERBARA, R.L.L. Respostas de Acacia mangium Willd e Sclerolobium paniculatum Vogel a fungos micorrízicos arbusculares nativos provenientes de áreas degradadas pela mineração de bauxita na Amazônia. Acta Bot. Bras., 18:141-149, 2004

MARTINS, S.G.; SILVA, M.L.N.; CURI, N.; FERREIRA, M.M.; FONSECA, S. \& MARQUES, J.J. G.S.M. Perdas de solo e água por erosão hídrica em sistemas florestais na região de Aracruz (ES). R. Bras. Ci. Solo, 27:395-403, 2003.

MOTA, P.E.F. O recurso natural do solo. Inf. Agropec., 7:3-7, 1981.

PIRES; L.S. \& SILVA, M.L.N. \& CURI, N. LEITE, F. P. Erosão hídrica em floresta de eucalipto pós-plantio na região centro leste de minas gerais. Lavras, Universidade Federal de Lavras, 2005. 4p. (Não Publicado)

RAMALHO FILHO, A. \& BEEK, K.J. Sistema de avaliação da aptidão agrícola das terras. Rio de Janeiro, Embrapa CNPS, 1995.

SCHAEFER, C.E.R.; SILVA, D.D.; PAIVA, K.W.N.; PRUSKI, F.F.; ALBUQUERQUE FILHO, M.R. \& ALBUQUERQUE, M.A. Perdas de solo, nutrientes, matéria orgânica e efeitos microestruturais em argissolo vermelho-amarelo sob chuva simulada. Pesq. Agropec. Bras., 37:669-678, 2002.

SCHAEFER, C.E.R. Ecogeography and human scenario in Northeast Roraima, Brazil. J. Braz. Assoc. Adv. Sci., 49:241-252,1997.

SEGANFREDO, M.L.; ELTZ, F.L.F. \& BRUM, A.C.R. Perdas de solo, água e nutrientes por erosão de sistemas de culturas em plantio direto. R. Bras. Ci. Solo, 21:287-291, 1997.

SOUZA, Z.M.; MONTANARI, R.; FILHO, M.V.M.; MARQUES JR, J. \& PEREIRA, G.T. Variabilidade espacial de fatores de erosão em latossolo sob diferentes formas de relevo. In: REUNIÃO BRASILEIRA DE MANEJO E CONSERVAÇÃO DO SOLO E DA ÁGUA, MANEJO INTEGRADO A CIÊNCIA DO SOLO NA PRODUÇÃO DE ALIMENTOS, 15., Santa Maria, 2004. Anais. Santa Maria, Universidade Federal de Santa Maria, 2004.

VALE JÚNIOR, J.F. Pedogênese e alterações dos solos sob manejo itinerante, em áreas de rochas vulcânicas ácidas e básicas, no nordeste de Roraima. Viçosa, MG, Universidade Federal de Viçosa, 2000. 185p. (Tese de Doutorado)

VALE JÚNIOR, J.F. \& LEITÃO E SOUSA, M.I. Caracterização e distribuição dos solos das savanas de Roraima. In BARBOSA, R.I. \& XAUD, H.A.M. \& SOUZA, J.M.C. Savanas de Roraima: Etnoecologia, biodiversidade e potencialidades agrosilvopastoris. Boa Vista, FEMACT, 2005. p.79-91.

VALE JÚNIOR, J.F.; SCHAEFER, C.E.G.R. \& COSTA, J.A.V. Etnopedologia e transferência de conhecimento: Diálogo entre os saberes indígenas e técnico na Terra Indígena Malacacheta, Roraima. R. Bras. Ci. Solo, 31:403-412, 2007 